\title{
Lead-Bismuth Eutectic Compatibility with Materials in the Concept of Spallation Target for ADS*
}

\author{
Kenji KIKUCHI ${ }^{* *}$, Shigeru SAITO**, Yuji KURATA** ${ }^{* *}$ Masatoshi FUTAKAWA**, \\ Toshinobu SASA ${ }^{* *}$, Hiroyuki OIGAWA**, Eiichi WAKAI**, Makoto UMENO***, \\ Hiroshi MIZUBAYASHI**** and Kuniaki MIURA ${ }^{\dagger}$
}

\begin{abstract}
Lead bismuth eutectic (LBE) is favored by spallation neutron sources and coolant in the sub-critical reactor at the accelerator driven nuclear transmutation system (ADS). Technical issues of ADS are material technology of how to compromise with flowing lead bismuth, high-energy proton accelerator technology and a sub-critical reactor system technology. This paper describes LBE technology developed at JAERI. First a scenario in order to realize the ADS is shown. The concept of spallation target test facility is introduced with a target design of thermo-fluid dynamics. Base data of flow rate and temperature of $\mathrm{Pb}-\mathrm{Bi}$ during $\mathrm{LBE}$ circulation are described. The results of LBE loop operation under the flowing conditions of target design concept are reported. The stagnant corrosion tests were done to know the controlling parameters among the various steels. The tube-type oxygen sensor with having the solid electrolyte was studied. Cleaning techniques were developed to remove LBE from materials.
\end{abstract}

Key Words: Erosion, Corrosion, Electro-Magnetic Pump, Lead-Bismuth Eutectic, Spallation, Electro-Magnetic Flow Meter, Accelerator Driven System, Oxygen Sensor, Cleaning Techniques

\section{Introduction}

The ADS aims at reducing the amount of the minor actinide (MA) and the long-lived fission products (LLFP) in the high level radioactive waste. The Japan Atomic Energy Research Institute (JAERI) proposed the $800 \mathrm{MWt}$, nitride fueled, $\mathrm{Pb}-\mathrm{Bi}$ eutectic cooled fast subcritical core driven by the spallation neutron source using $\mathrm{Pb}$-Bi target and $1.5 \mathrm{GeV}, 20-30 \mathrm{MW}$ proton accelerator ${ }^{(1)}$.

The scenario to realize the Accelerator Driven transmutation System (ADS) consists of four steps as follows:

Step-I, a development of base technology on a flow-

* Received 30th October, 2003 (No. 03-4149)

** Tokai Research Establishment, Japan Atomic Energy Research Institute, Tokai-mura, Ibaraki 319-1195, Japan. Email:kikuchi@popsvr.tokai.jaeri.go.jp

*** Mitsubishi Heavy Industry Co., Ltd., Minato-mirai, Yokohama, Kanagawa 220-8401, Japan

**** Mitsui Engineering \& Ship-building Co., Ltd., Tsukiji, Tokyo 104-8439, Japan

† Sukegawa Electric Co., Ltd., Takahagi-shi, Ibaraki 3180004, Japan ing $\mathrm{Pb}-\mathrm{Bi}$, and establishment of base technology on controlling devices.

Step-II, a construction of the transmutation experimental facility equipped with $\mathrm{Pb}-\mathrm{Bi}$ target and $200 \mathrm{~kW}$ proton beams and a zero-power critical assembly ${ }^{(2)}$.

Step-III, a construction of experimental ADS with $80 \mathrm{MWt}, \mathrm{Pb}$-Bi target/coolant and partial MA nitride fuel region.

Step-IV, a construction of ADS transmutation plant with $800 \mathrm{MWt}$ and $\mathrm{Pb}-\mathrm{Bi}$ target/coolant, which is to transmute $250 \mathrm{~kg}$ MA annually.

Step-I program is under way and step-II program is planned under the joint project with the High Energy Accelerator Research Organization (KEK) on high intensity proton accelerator program called J-PARC (Japan Proton Accelerator Research Complex) ${ }^{(3)}$. A Transmutation Experimental Facilities (TEF) is planned for construction. The TEF consists of two concepts: ADS Target Test Facility and the Transmutation Physics Experimental Facility as shown in Fig. 1. The ADS target test facility aids in doing engineering tests for establishing a $\mathrm{Pb}-\mathrm{Bi}$ spallation 


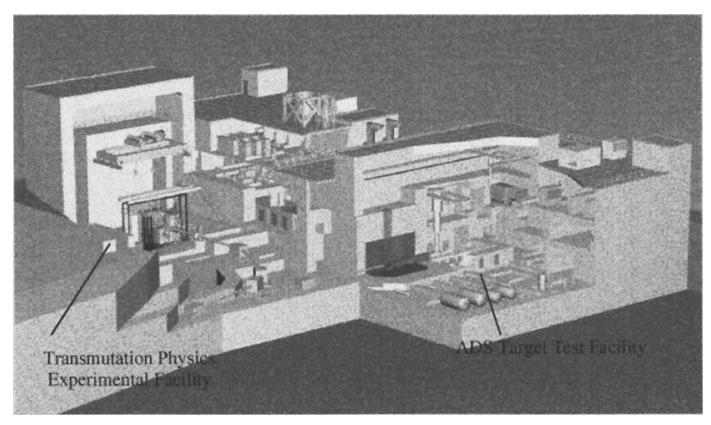

Fig. 1 Transmutation experimental facility

target technology $\mathrm{y}^{(4)}$.

At TEF, materials irradiation examination will be carried out with research \& development relevant to the $\mathrm{Pb}$ $\mathrm{Bi}$ target and containment material performance. The target will be bombarded by protons, which are accelerated by the normal state conductivity linear accelerator to $400 \mathrm{MeV}$ and by the superconductivity linear accelerator to $600 \mathrm{MeV}$. The incident proton cycle is $25 \mathrm{~Hz}$ with a long pulse of $0.5 \mathrm{~ms}$.

In order to make design base for the ADS target test facility the research and development covers $\mathrm{Pb}-\mathrm{Bi}$ technology, radiation effects of materials, target design with computer simulation and handling technology of spallation products. $\mathrm{Pb}-\mathrm{Bi}$ technology consists of flowing loop test, stagnant corrosion test, the development of oxygen sensor and cleaning techniques. In the flowing loop test the experimental items are verification of feasibility of existing materials for the facility construction, the development of devices such as electro-magnetic pump (EMP), electro-magnetic flow meter (EMF), $\mathrm{Pb}$-Bi level meter, filtering device and accumulation of experiences. Stagnant corrosion test mainly aims at corrosion test under controlled condition of oxygen potential. Oxygen sensors are being developed in order to achieve good performance at the low temperature around $450^{\circ} \mathrm{C}$ by using reference electrode such as $\mathrm{Pt} /$ air, $\mathrm{In} / \mathrm{In}_{2} \mathrm{O}_{3}$ and $\mathrm{Bi} / \mathrm{Bi}_{2} \mathrm{O}_{3}$.

\section{Target Design for Test Facility}

The incident proton power is $200 \mathrm{~kW}: 600 \mathrm{MeV}$ and $0.333 \mathrm{~mA}$ at a frequency of $25 \mathrm{~Hz}$ with a pulse width of $0.5 \mathrm{~ms}$. Technical issue is the target window performance. High-energy incident protons penetrate the target window and deposit heat in $\mathrm{Pb}-\mathrm{Bi}$ and the target vessel. Materials were irradiated at SINQ target $3^{(5)}$ and tested at JAERI Hot Cell. Emphases must be put on the cooperative effect of the radiation and the flowing $\mathrm{Pb}-\mathrm{Bi}$ on the materials in ADS.

Figure 2 shows a computer simulation (STAR-CD) ${ }^{(6)}$ of the velocity of $\mathrm{Pb}-\mathrm{Bi}$ in the frame of the half model of the design concept of spallation target. Incident protons are injected from the left to the target. In the target

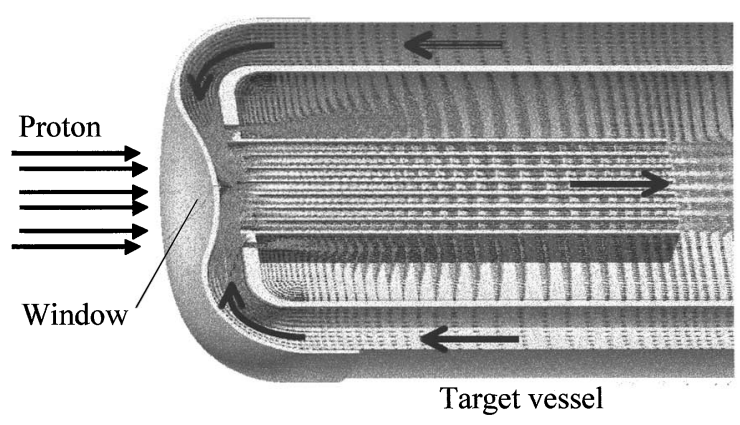

Fig. 2 The concept of $\mathrm{Pb}-\mathrm{Bi}$ target

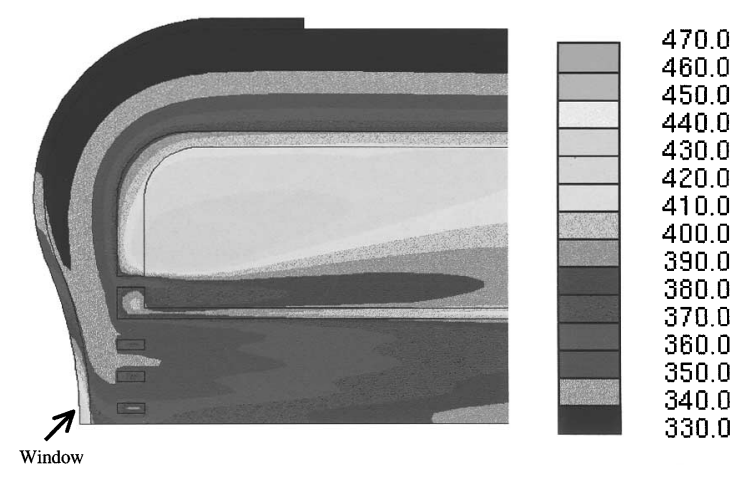

Fig. 3 Temperature distribution in $\mathrm{Pb}-\mathrm{Bi}$ target (half model). Unit: ${ }^{\circ} \mathrm{C}$

with co-axial double walls $\mathrm{Pb}$ - $\mathrm{Bi}$ flows to the direction indicated by arrows. $\mathrm{Pb}-\mathrm{Bi}$ flows in the annular channel, returns at window and flows to the right side. There are plates in the center that would be samples for post irradiation examinations. This is an idea to know the cooperative effect by $\mathrm{Pb}-\mathrm{Bi}$ and protons. Stripes in plotting showed the magnitude of velocity of $\mathrm{Pb}-\mathrm{Bi}$ in arbitrary unit. Figure 3 shows the temperature distribution in the target near window. It appeared that the design base temperature and the flow velocity are about $450^{\circ} \mathrm{C}$ and $1 \mathrm{~m} / \mathrm{s}$ at the target window, respectively.

\section{Lead-Bismuth Loop}

\subsection{Description of test loop}

A flow diagram of lead-bismuth circulating loop for materials corrosion was already reported ${ }^{(2)}$. The main circulating loop consists of an electro-magnetic pump (EMP), a heater, test specimen tubes at high and low temperatures, $\mathrm{Pb}$-Bi filters, a surge tank, a cooler, an electromagnetic flow meter (EMF), a surface-level meter, thermocouples, an observation window, and a drain tank. The $\mathrm{Pb}$-Bi filters as well as the test specimen tube at low temperature were additional function. They were installed into the loop after first $3000 \mathrm{hrs}$ circulation test at the upstream of EMF, the downstream of EMP and the bypass line to the drain tank as shown in Fig. 4. EMP is a linear inductive type with an annular channel. EMF has two 


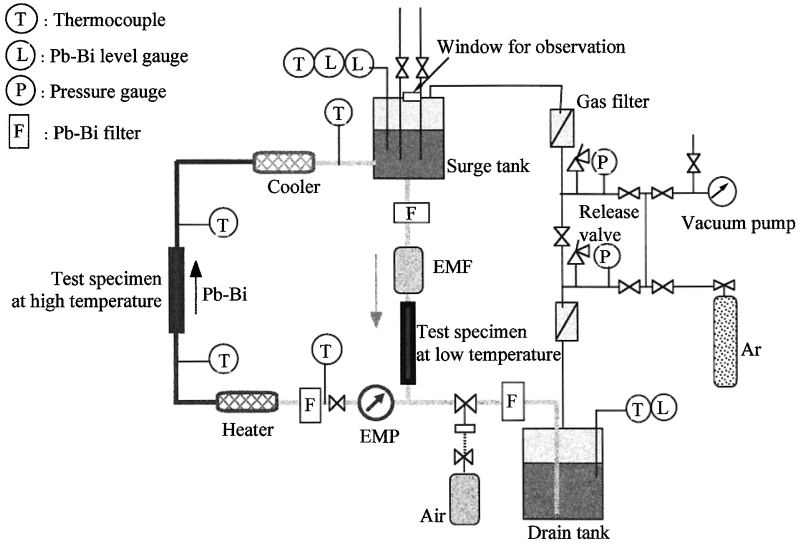

Fig. 4 A flow diagram of $\mathrm{Pb}-\mathrm{Bi}$ circulating loop

electrodes in contact with $\mathrm{Pb}-\mathrm{Bi}$ that detect electromotive force in the magnetic fields. During operation, the maximum temperature, the temperature difference and the flow velocity of $\mathrm{Pb}-\mathrm{Bi}$ at the specimen were $450^{\circ} \mathrm{C}, 50^{\circ} \mathrm{C}$, and about $1 \mathrm{~m} / \mathrm{s}$, respectively. Oxygen was not actively controlled in the experiment. The argon gas of 99.95 mass\% purity covered the top plenum void of the surge tank during operation. A portion of $\mathrm{Pb}-\mathrm{Bi}$ was sampled from the adhered $\mathrm{Pb}-\mathrm{Bi}$ on the specimen and melted in the retort after pre-treatment. Oxygen concentration in the sample was measured to be $1 \times 10^{-3}$ mass $\%$ by infrared spectroscopic analysis. The saturation concentration of the oxygen in $\mathrm{Pb}-\mathrm{Bi}$ at the operation temperature of $450^{\circ} \mathrm{C}$ is calculated as $3.2 \times 10^{-4}$ mass $\%^{(7)}$.

\section{2 Material preparation}

Materials for tube and tanks that contact $\mathrm{Pb}-\mathrm{Bi}$ in the loop were made of SUS316.

Testing specimen tube is a cold-drawn seamless type SUS316, which was produced as a tubing form with $13.8 \mathrm{~mm}$ outer diameter, $2 \mathrm{~mm}$ thickness and $40 \mathrm{~cm}$ length. The tube was solution-heat treated at $1080^{\circ} \mathrm{C}$ for $1.5 \mathrm{mins}$. and then cooled rapidly. Acid washing was performed to remove the oxide layer after heat treatment in the furnace. Other tubes in the circulating loop, except for the testing tube, were cold-drawn products with $27.2 \mathrm{~mm}$ outer diameter and $2.5 \mathrm{~mm}$ thickness. This means that the maximum velocity of $\mathrm{Pb}$-Bi will occur at the high-temperature specimen. The chemical composition of $\mathrm{Pb}-\mathrm{Bi}$ is $\mathrm{Bi} 55 / \mathrm{Pb} 45$ (wt\%). The $\mathrm{Pb}-\mathrm{Bi}$ filter consists of curling thin foils made of SUS430, which was packed in the cylindrical vessel as shown in Fig 5.

\subsection{Stability of circulating $\mathrm{Pb}-\mathrm{Bi}$ parameters}

In the first $3000 \mathrm{hrs}$ operation of the loop maximum temperature was kept to $450^{\circ} \mathrm{C}$ and the difference of temperature was $50^{\circ} \mathrm{C}$. Figure 6 shows the stability of controlled temperature in the circulating loop during Jan.29 to Mar.25, in 2001, for example. However, flow control was not stable. Figure 7 shows instability of flow rate

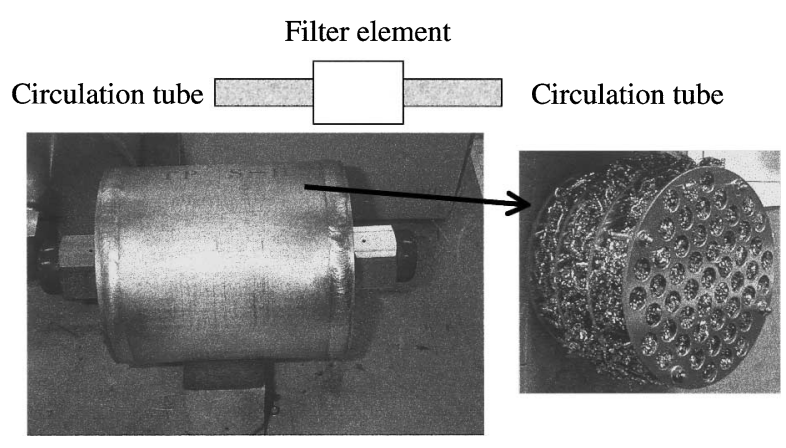

Fig. 5 Filter element

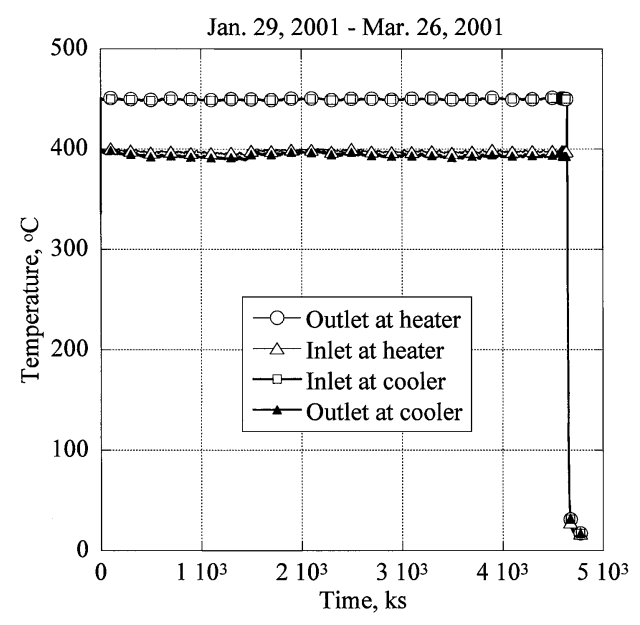

Fig. 6 Stability of controlled temperature in the flowing loop

during operations. Scheduled flow rate was 5 liters per minutes: it corresponded to $1 \mathrm{~m} / \mathrm{s}$ at the high temperature specimen and $0.2 \mathrm{~m} / \mathrm{s}$ at the low temperature specimens, respectively. At a time of 1300 and $2500 \mathrm{hrs}$ the $\mathrm{Pb}$ Bi flow was interrupted by the calibration process of the electro-magnetic flow meter. The calibration was done by measuring a time that a particular volume of $\mathrm{Pb}-\mathrm{Bi}$ in the surge tank drops into the dump tank under the gravitation force. Figure 8 shows the results of EMF calibration. In comparison with the initial condition of flow rate the susceptibility of EMF was enhanced after $1300 \mathrm{hrs}$ and kept stable. After the calibration of flow meter at $2500 \mathrm{hrs}$ the flow rate recovered abruptly. In these operations the input current in EMP was almost kept the same. This means the magnetic fields were almost constant and so the driving force to $\mathrm{Pb}-\mathrm{Bi}$ was the same. Again the continuous decreasing of the flow rate was observed.

After operation specimen was removed from the loop and the cross section was examined by digital microscope. It appeared that the reason was attributed to an increase of flow resistance in the channel of EMP. Dissolved elements from stainless steel into $\mathrm{Pb}-\mathrm{Bi}$ at high temperature precipitated in the flow channel accompanied with $\mathrm{Pb}-\mathrm{Bi}$ in the 


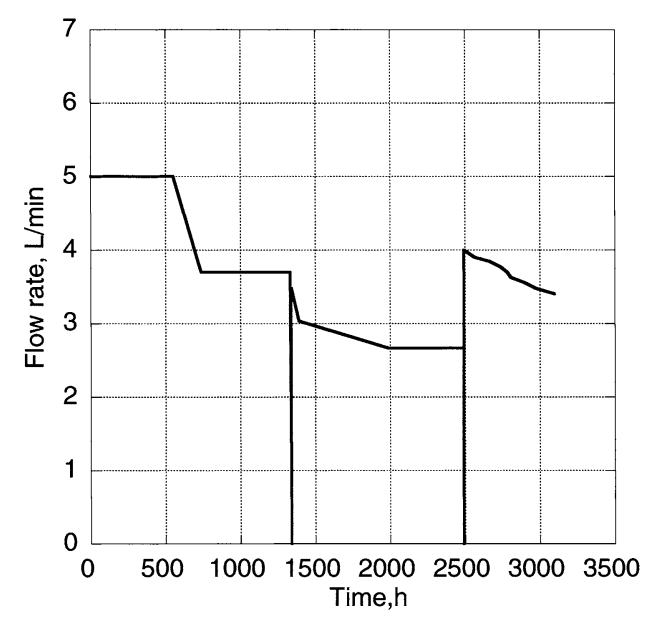

Fig. 7 Instability of EMF output in the first $3000 \mathrm{hrs}$ test

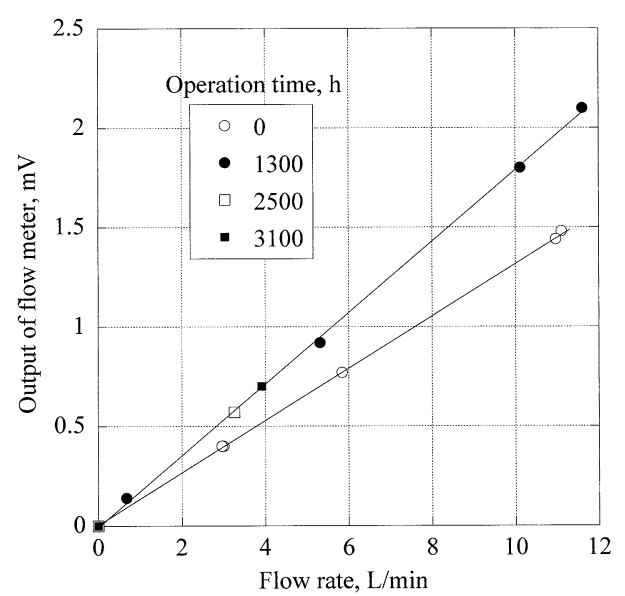

Fig. 8 Performance curve of electro-magnetic flow meter

upstream of EMP. However, the precipitation was not occurred in the downstream of EMP because the temperature was $400^{\circ} \mathrm{C}$ at the EMP inlet and presumably $420^{\circ} \mathrm{C}$ at the EMP outlet. As the precipitation site is limited in the lower temperature site, the narrowed channel was only the upstream area. These materials narrowed the flow channel of EMP and increased flow resistance. So the flow channel was double-widen before the second $3000 \mathrm{hrs}$ test. As results significant decreasing of flow rate was not observed as shown in Fig. 9 but still there was a scatter in the flow rate. The reason of small instability is under investigation.

Figure 10 shows the tip of EMF electrode. There are two electrodes in the flow meter at the opposite directions in the cross-section of the tube. Electromotive force will be provided between two electrode-tips, which contact with flowing $\mathrm{Pb}-\mathrm{Bi}$ in the magnetic field. The tip shape was a circular cone with $0.5 \mathrm{~mm}$ height. But after $3000 \mathrm{hrs}$ in service the tip was eroded to $0.1 \mathrm{~mm}$ height. Further examination is needed to know the relation between the instability of flow rate measurement and erosion

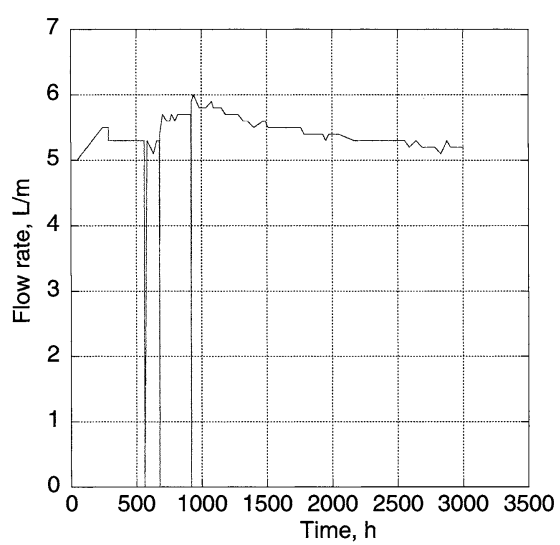

Fig. 9 Instability of EMF output in the second 3000 hrs test

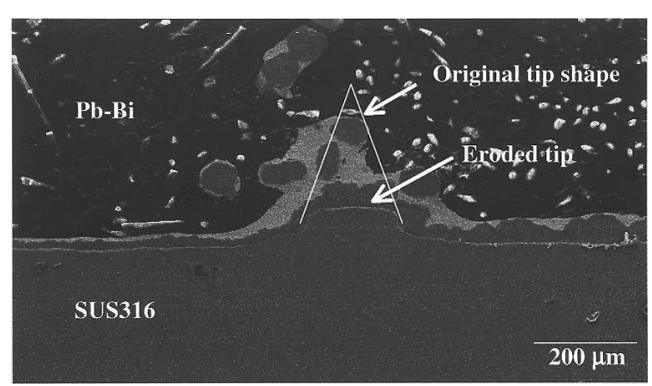

Fig. 10 Eroded tip of EMF
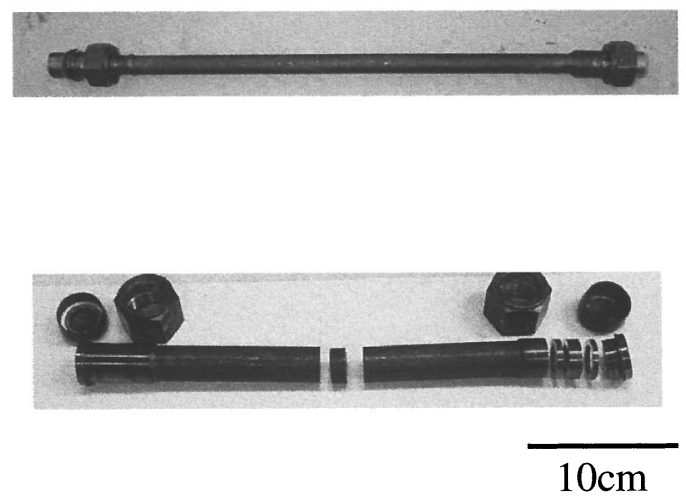

Fig. 11 Specimens at high (top) and low (bottom) temperatures

of tips in the EMF.

\section{4 Corrosion-erosion of SUS316}

Main concern is compatibility of materials under flowing Pb-Bi. After the first $3000 \mathrm{hrs}$ test we examined high temperature specimen and tubes at low temperature. Then the low temperature specimen was added in the loop. After the second $3000 \mathrm{hrs}$ test we again examined high- and low-temperature specimens and observed the inner surfaces and the cross sections. Figure 11 shows the high-temperature and low temperature specimens. The low temperature specimen was already cut for the inspection in this figure. We used unpolished speci- 


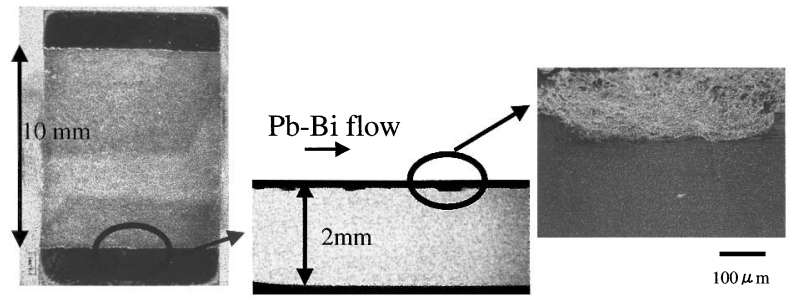

Fig. 12 Unpolished high-temperature specimen

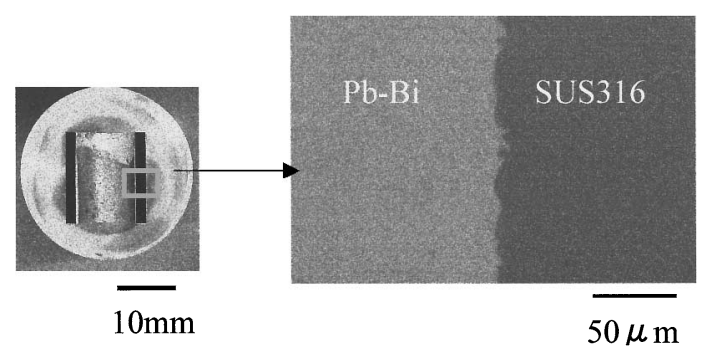

Fig. 13 Polished high-temperature specimen

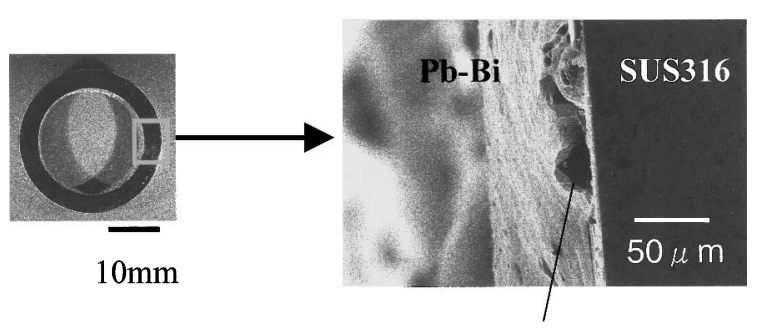

Precipitated materials

Fig. 14 Unpolished low-temperature specimen

mens at high and low temperatures in the first operation, and polished specimen at high temperature and unpolished specimen at low temperature in the second operation, respectively. Figure 12 shows the cross section of unpolished high-temperature specimen. The inner surface was locally corroded. Corrosion was not uniform in the test specimen: the corrosion depth was deeper in the downstream portion than the upstream in the test specimen. But it was unclear that this phenomenon was true or not in the overall circulating tubes at high temperature. The maximum depth was evaluated to $100 \mu \mathrm{m}$ at the downstream and $30 \mu \mathrm{m}$ at the upstream within the specimens, respectively. Figure 13 shows the cross section of polished high-temperature specimen after the second 3000 hrs test. The high temperature specimen was polished by sand paper of \#800 before the test. It appeared that the corrosion depth was roughly $20 \mu \mathrm{m}$. This suggests polished surface enhances the endurance of material with $\mathrm{Pb}$ Bi. Figure 14 shows the cross section of unpolished lowtemperature specimen. The materials were not corroded. And precipitated materials were seen in the $\mathrm{Pb}-\mathrm{Bi}$ adhered
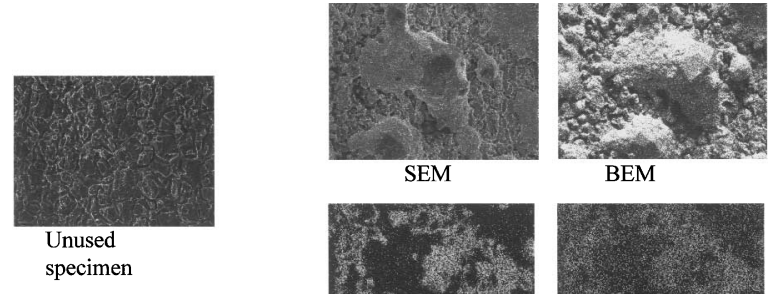

SEM

BEM
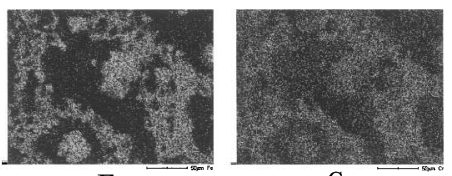

$\mathrm{Fe}$

$\mathrm{Cr}$

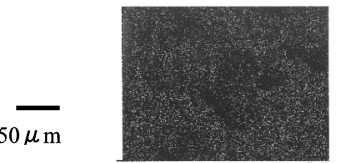

$\mathrm{Ni}$

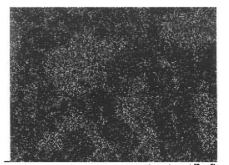

$\mathrm{Pb}$

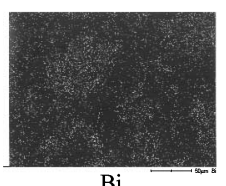

$\mathrm{Bi}$
Fig. 15 EDX analyses of low-temperature specimen
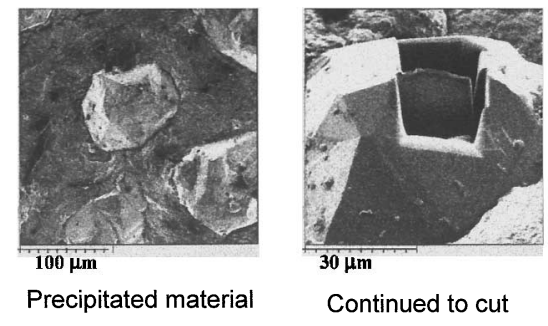

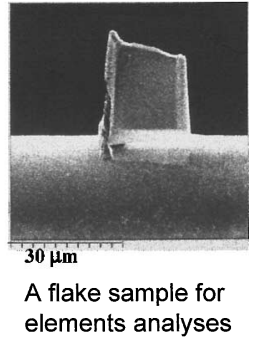

Fig. 16 A flake sample (right) cut from precipitated material (left) by means of focused ion beams

on the wall of SUS316 tube. Figure 15 shows the inner surface of the low-temperature specimens before and after the test. The surface of unused specimen was characterized by the creviced structure. This feature resulted from the acid washing in the manufacturing process as mentioned in the material preparation. The inner surfaces of high-temperature specimens are also seen like this morphology. There are precipitated materials on the tube. The precipitation materials consist of mainly $\mathrm{Fe}$ and $\mathrm{Cr}$ as a result of energy dispersive X-ray analyses and apparently look crystals. We analyzed one of the crystals by means of a focused-ion beam, X-rays and TEM. Figure 16 shows the process of making a flake sample cut from the crystal. Figure 17 shows TEM bright field image. As a result of the quantitative analysis of deposit crystal by X-rays, $\mathrm{Fe}$ and $\mathrm{Cr}$ were detected and the weight concentration ratio was roughly $\mathrm{Fe}: \mathrm{Cr}=9: 1$. Nickel was not found in the polycrystals ${ }^{(8)}$. They were precipitations from $\mathrm{Pb}-\mathrm{Bi}$ including impurities dissolved from SUS316 at the high temperature part. It is found that they are ferritic alloys. Consequently it is emphasized that the precipitation happened in the channel of EMP. And the flow resistance was increased as mentioned in the previous section. The precipitation materials are the same with mentioned here. The ferrite materials are easy to be trapped at the magnetic 


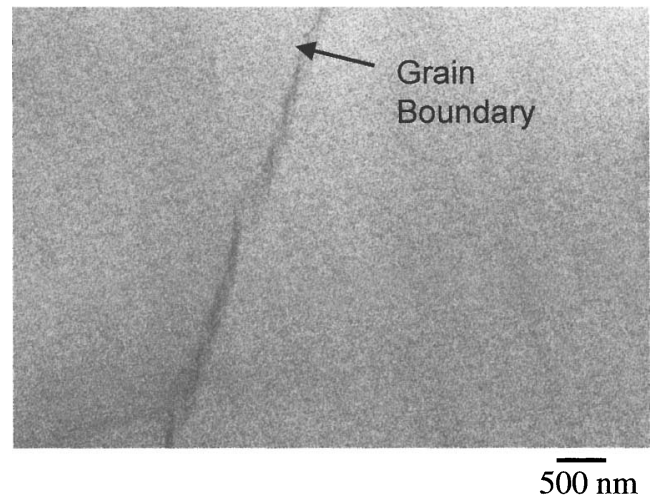

Fig. 17 TEM bright field image: Grain boundary appeared in flake

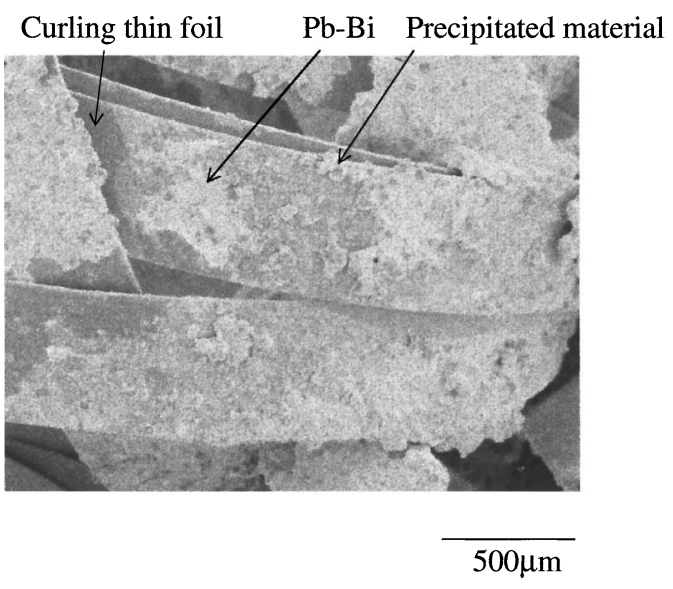

Fig. 18 SEM image of the curling thin foils

field inside the pump. In addition we inspected the filter element after $3000 \mathrm{hrs}$ operation. The filter elements were also installed at lower temperature part as described in the section 3.1. Figure 18 shows SEM image of the curling thin foils, which consist of the filter element. The $\mathrm{Fe}-\mathrm{Cr}$ polycrystals were buried in the $\mathrm{Pb}-\mathrm{Bi}$ adhered on the foils.

\section{Stagnant Corrosion Test}

\subsection{Corrosion test equipment}

Figure 19 shows static corrosion equipment. The retort contacting liquid $\mathrm{Pb}-\mathrm{Bi}$ is made of quart $\mathrm{z}^{(9)}$. Purging gas of a constant $\mathrm{H}_{2} / \mathrm{H}_{2} \mathrm{O}$ ratio is a good methodology to control oxygen concentration in liquid $\mathrm{Pb}-\mathrm{Bi}$. The test temperature will range between $350^{\circ} \mathrm{C}$ and $600^{\circ} \mathrm{C}$. In the experiment reported here $\mathrm{Ar}$ gas containing several percentage of oxygen was used as cover gas over liquid $\mathrm{Pb}$ Bi. $\mathrm{PbO}$ with about $1 \mathrm{~mm}$ thickness formed on the surface of the liquid $\mathrm{Pb}-\mathrm{Bi}$ during the corrosion test. The specimens were pulled out from the liquid $\mathrm{Pb}-\mathrm{Bi}$ when the experiment was completed and cooled in the cover gas. Although test specimens were washed in the silicon oil at about $170^{\circ} \mathrm{C}$, adherent $\mathrm{Pb}$-Bi could not be removed from

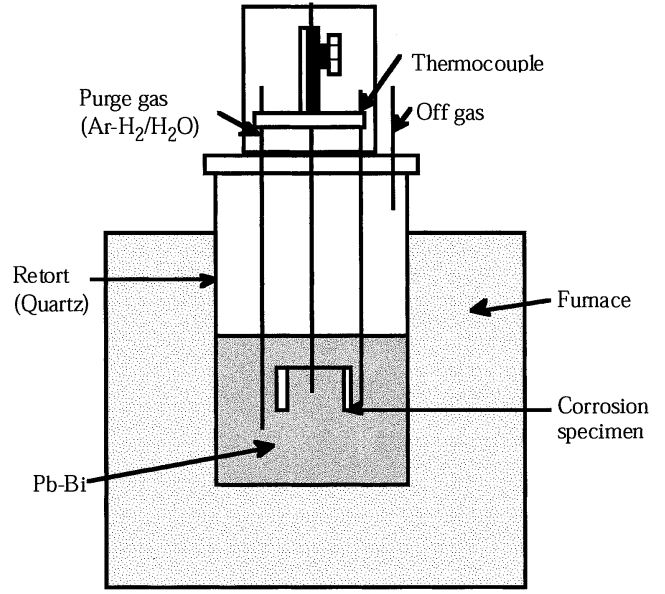

Fig. 19 Stagnant corrosion test equipment

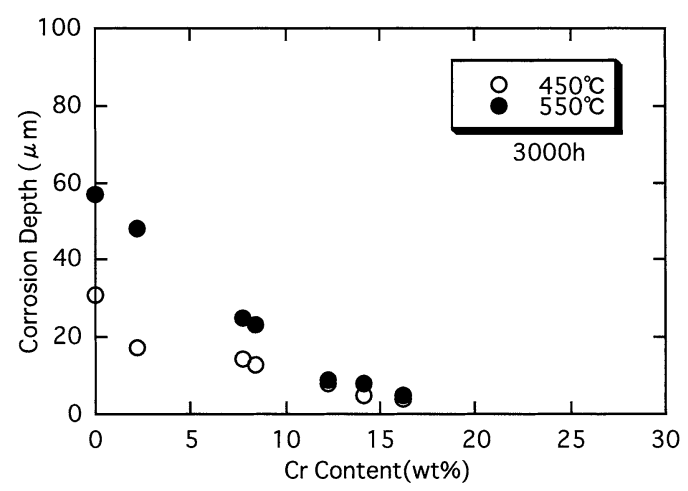

Fig. 20 Corrosion depth in the stagnant tests

the specimen surface completely. The cross-section of the tested specimens was observed using optical microscope after cutting the corrosion specimens.

\section{2 Materials compatibility in stagnant $\mathrm{Pb}-\mathrm{Bi}$}

Tested materials in saturated oxygen content are pure $\mathrm{Fe}, 2.25 \mathrm{Cr}-\mathrm{Fe}$ steel (Cr 2.18 mass\%), $\mathrm{F} 82 \mathrm{H}(\mathrm{Cr}$ 7.72 mass\%), ${ }^{(10)}$ Mod.9Cr-1Mo steel (Cr 8.41 mass\%), SS410 (Cr 12 mass\%), JPCA (Cr 14 mass\%), and SS430 (Cr 16.24\% mass\%). Figure 20 shows the relationship between the corrosion depth and the $\mathrm{Cr}$ content in steels. Tested temperatures were 450 and $550^{\circ} \mathrm{C}$ in oxygen saturated $\mathrm{Pb}-\mathrm{Bi}$ for $3000 \mathrm{hrs}$, respectively. The corrosion depth of JPCA was $5 \mu \mathrm{m}$. In comparison with the results of the previous section, this corrosion depth is different from the results of flowing test. Anyhow it appeared that a corrosion rate was very affected by a flow speed of $\mathrm{Pb}$ $\mathrm{Bi}$. Other important results are the effect of $\mathrm{Cr}$ content on the corrosion thickness in $\mathrm{Pb}-\mathrm{Bi}$. JPCA showed minimum values of corrosion thickness among them. The corrosion thickness decreases with increasing $\mathrm{Cr}$ content. 

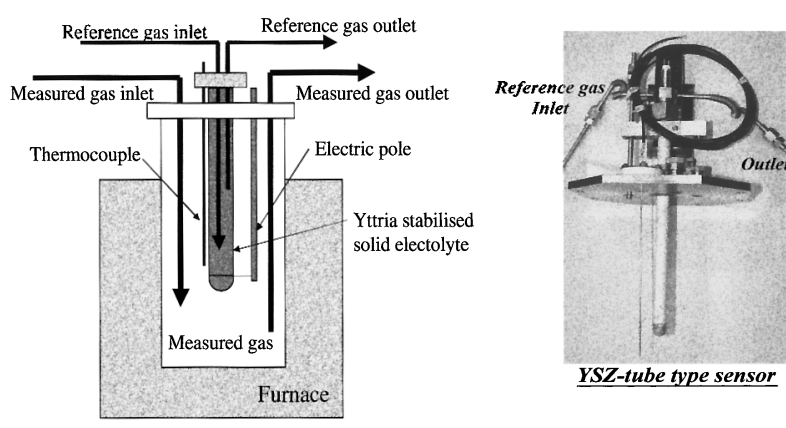

Fig. 21 Oxygen sensor

\section{Oxygen Sensor}

The formation of the protective oxide layer is key issue to compromise with materials performance in $\mathrm{Pb}-\mathrm{Bi}$, especially at high temperature. The oxide layer is dependent on the oxygen content in $\mathrm{Pb}-\mathrm{Bi}$. The development of the on-line monitoring and controlling system of the oxygen content in the $\mathrm{Pb}-\mathrm{Bi}$ has been studied.

First a tube-type oxygen sensor was made using the solid electrolyte of yttria-stabilized zirconia, YSZ (8mole $\% \mathrm{Y}_{2} \mathrm{O}_{3}$ ) as shown in Fig. 21. The basic characteristics have been investigated under the gas/gas and the gas/ $\mathrm{Pb}-\mathrm{Bi}$ melt environments; i.e. the reference gas is the He gas with $10 \%$ oxygen and the oxygen content of the measured gas is varied from $0.05 \%$ to $0.1 \%$, and the air used as reference gas/Pb-Bi with saturated oxygen concentration. The temperature ranges from 350 to $600^{\circ} \mathrm{C}$. The potentiometer for high impedance, KEITHLEY617, is employed. The dependency of the measured voltage on temperature was validated under the stable condition with sufficient holding time. The measured voltage under the stable condition was describable by the theoretical formulation in the gas/gas throughout the temperature range and in the air/ $\mathrm{Pb}-\mathrm{Bi}$ at the temperature higher than $450^{\circ} \mathrm{C}$. The study is extended to other oxide references as $\mathrm{In} / \mathrm{In}_{2} \mathrm{O}_{3}$ and $\mathrm{Bi} / \mathrm{Bi}_{2} \mathrm{O}_{3}$.

\section{Cleaning Techniques}

$\mathrm{Pb}$-Bi cleaning technology is another key issue in order to reduce radiation exposure during maintenance service, to decontaminate exchanged components and to prepare specimens for the post irradiation examination.

Two types of cleaning methods were tested; those were silicon oil at $180^{\circ} \mathrm{C}$ and mixture of acetic acid, hydrogen peroxide and ethanol (1:1:1). Specimens were immersed in liquid $\mathrm{Pb}-\mathrm{Bi}$ at $400^{\circ} \mathrm{C}$ during $250 \mathrm{hrs}$ and pulled out from the retort. Then specimens were immersed during 90 mins. in the oil or in the mixed acid. Tested material was SUS316L at $30 \mathrm{~mm}$ length, $15 \mathrm{~mm}$ width and $2 \mathrm{~mm}$ thickness.

Figure 22 shows specimen before and after cleaning
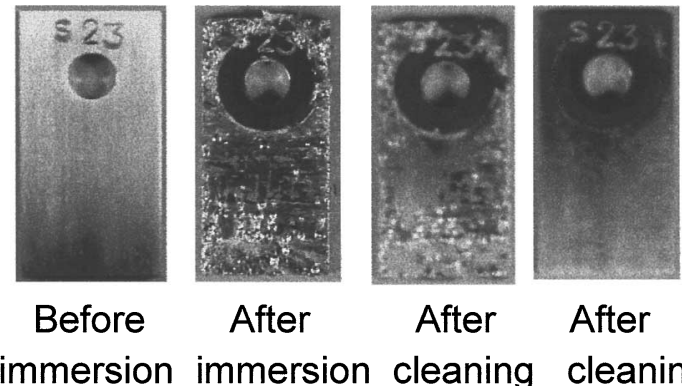

After

After

After immersion

immersion

cleaning

cleaning

\& blushing

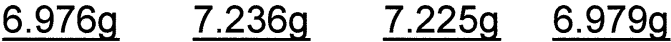

Fig. 22 Macroscopic photographs and weight of specimen in the silicon oil

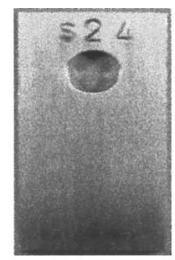

Before immersion $\underline{6.997 \mathrm{~g}}$

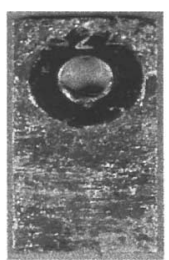

After immersion 7.132g

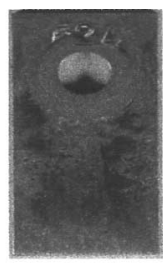

After cleaning $\underline{7.001 \mathrm{~g}}$
Fig. 23 Macroscopic photographs and weight of specimen in the mixed acid

in the silicon oil. Numerical values indicate weight of the specimen. It was found that blushing process was needed to remove $\mathrm{Pb}$-Bi effectively for the specimens immersed in the silicon oil. Figure 23 shows that the mixed acid easily dissolved $\mathrm{Pb}-\mathrm{Bi}$ and removed almost perfectly. But specimens themselves were also tinted as a result of chemical reaction.

\section{Conclusions}

In order to construct ADS target test facility in JPARC project the research and development on the base technology for the lead-bismuth eutectic compatibility with materials in the concept of spallation target have been carried, which cover target design with computer simulation under the incident protons, flowing loop test, stagnant corrosion test, oxygen sensor and cleaning techniques. Obtained results are as follows:

- Corrosion rate of SU316 under flowing $\mathrm{Pb}-\mathrm{Bi}$ at $1 \mathrm{~m} / \mathrm{s}$ at $450^{\circ} \mathrm{C}$ is $0.1 \mathrm{~mm} / 3000 \mathrm{hrs}$.

- $\mathrm{Fe}$ and $\mathrm{Cr}$ were melted into lead bismuth from SUS316 in the high temperature part and deposited in the low-temperature part according to the difference of solubility. The polycrystals increased the flow resistance in the electro-magnetic pump.

- The corrosion thickness decreases with increasing 
$\mathrm{Cr}$ content in the stagnant corrosion test at saturated oxygen concentration.

- Oxygen sensors are to be developed by using reference electrodes.

- In cleaning techniques, blushing process was needed to remove $\mathrm{Pb}$ - $\mathrm{Bi}$ effectively after immersion in the silicon oil. The mixed acid easily dissolved $\mathrm{Pb}-\mathrm{Bi}$ and removed almost perfectly. But specimens themselves were also tinted.

\section{Acknowledgements}

We appreciate Mr. Kazuhiro Suzuki, student of Toyohashi University of Technology, for taking SEM photos of specimens.

\section{References}

( 1 ) Tsujimoto, K., Sasa, T., Nishihara, K., Takizuka, T. and Takano, H., Study of Accelerator-Driven System for Transmutation of High-Level Waste from LWR, ICONE-7, Tokyo, (1999).

( 2 ) Oigawa, H., Sasa, T., Ikeda, Y., Kikuchi, K., Maekawa, F., Meigo, S., Kasugai, Y., Tsujimoto, K., Nishihara, K., Konno, C., Kai, T., Takano, H. and Yamane, T., Conceptual Design of Transmutation Experimental Fa- cility, Global 2001, Paris, (2001).

( 3 ) The Joint Project for High-Intensity Proton Accelerators, JAERI-Tech 99-056, August (1999).

( 4 ) Kikuchi, K., Sasa, T., Ishikura, S., Mukugi, K., Kai, T., Ouchi, N. and Ioka, I., Current Status of JAERI Spallation Target Material Program, J. Nucl. Mater., Vol.x, (2001), pp.34-42.

( 5 ) Dai, Y. and Bauer, G.S., Status of the First SINQ Irradiation Experiment STIP-I, J. Nucl. Mater., Vol.296 (2001), pp.43-53.

( 6 ) Star-CD User Guide, (2002) CD Adaco Japan Co., Ltd.

( 7 ) Martynov, P., Orlov, Yu., Efanov, A., Troiynov, V., Resanov, A. and Lavrova, O., Technology of LeadBismuth Coolants for Nuclear Reactors, Proc. ISTCTITech Japan Workshop on Nuclear Reactor Technologies in Russia/CIS, (2001), pp.80-105.

( 8 ) Kikuchi, K., Kurata, Y., Saito, S., Futakawa, M., Sasa, T., Oigawa, H., Wakai, E. and Miura, K., CorrosionErosion Test of SS316 in Flowing Pb-Bi, J. Nucl. Mater., Vol.318 (2003), pp.348-354.

( 9 ) Kurata, Y., Futakawa, M., Kikuchi, K., Saito, S. and Osugi, T., Corrosion Studies in Liquid Pb-Bi Alloy at JAERI, J. Nucl. Mater., Vol.301 (2002), pp.28-34.

(10) Tamura, M., Hayakawa, H., Tanimura, M., Hishinuma, A. and Kondo, T., J. Nucl. Mater., Vol.141-143 (1986), p.1067. 